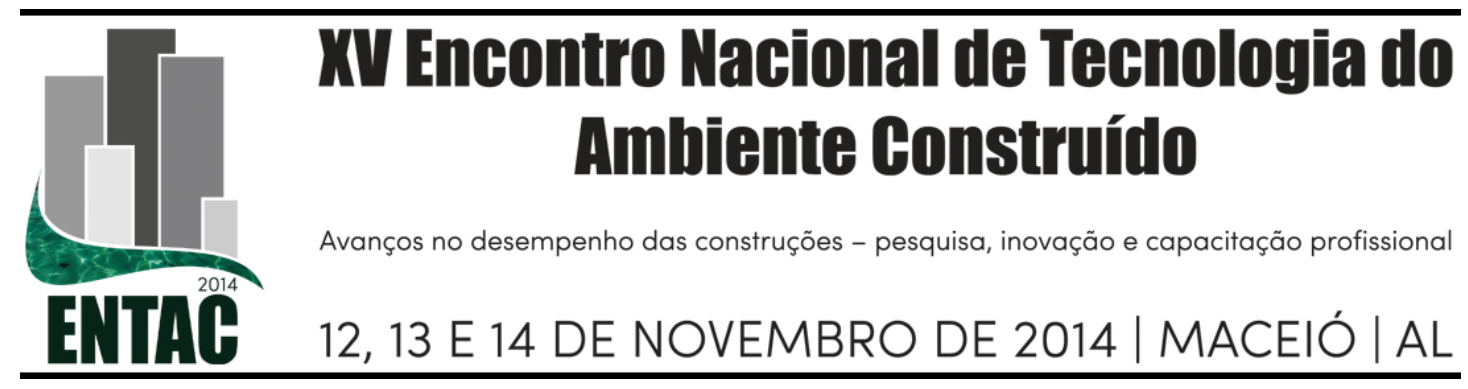

\title{
ANÁLISE DOS NÍVEIS DE CALOR E CONFORTO EM UMA OLARIA NO SUL DO BRASIL
}

\section{SILVA, Mayara Di Castro (1); IWAMURA, Corine Kyo (2); MARTINS, Giorgia Cristina (3); MATOS, Lucas Bilk (4); CATAI, Rodrigo Eduardo (5)}

(1) UTFPR, e-mail: maydicastro_2009@hotmail.com, (2) UTFPR, e-mail: corineiwamura@gmail.com, (3) UTFPR, e-mail: gcfariasm@ hotmail.com, (4) UTFPR, e-mail: lbilkm@gmail.com, (5) UTFPR, email: catai@utfpr.edu.br

\begin{abstract}
RESUMO
É cada vez mais comum e necessária a preocupação com o conforto nos ambientes de trabalho. Dentre as questões usualmente consideradas está o excesso de calor. Este pode constituir em um grave desconforto e até mesmo em risco de dano à saúde dos funcionários caso não se tome nenhum tipo de medida para evitar a exposição a este fator de risco. É de extrema importância, portanto, fazer o controle da temperatura nos postos de trabalho e saber a que condições os colaboradores estarão sujeitos para tomar as medidas necessárias, visando contribuir com o bem estar destes e até mesmo com a produtividade da empresa. O caso de estudo a ser descrito no presente artigo é o resultado de visitas técnicas em uma olaria localizada na região sul do Brasil e análises enfocando o conforto ambiental, principalmente nos aspectos relativos às altas temperaturas observadas, às condições ambientais nas quais seus trabalhadores se encontram continuamente expostos e às condições de trabalho submetidas. Utilizou-se um termômetro de globo do fabricante Instrutherm e as medidas foram realizadas nas regiões em que os operários trabalhavam e que estavam próximas aos fornos. A partir da interpretação crítica dos dados foi possível obter conclusões a respeito dos agentes de risco que afetam os colaboradores e a intensidade com que ocorrem. Propôs-se, por fim, mudanças ou melhorias necessárias e sugestões para amenizar e controlar os fatores causadores de um ambiente insalubre.
\end{abstract}

Palavras-chave: Conforto, Insalubridade, Calor, Olaria.

\begin{abstract}
The concerns about comfort in the work environment are increasing and becoming usual through time. Among the most considered questions is excessive heat, which may lead to serious discomfort and even to risk and hazard to workers' health. Therefore it is absolutely necessary to control temperature in workplaces and to know the conditions to which workers are exposed, aiming for improvements in their well-being and the enterprise productivity. The following article will describe the results from a case study consisting of technical visits to a brick factory situated in southern Brazil and further analyses of workplace and its comfort, focusing on high temperatures, exposition time and nature of task. The data obtained from the brick factory in Tatuquara - Curitiba, Paraná, were used to a graduation research project and were collected using a globe thermometer from Instrutherm, the readings took place near the workers surroundings next to the furnace. Through a critical interpretation of the information gathered, it was possible to understand where and how frequently workers are exposed to risks in the work environment. As a result, changes and improvements were proposed to minimize hazard from the unhealthy workplaces. This study was made aiming a better work environment, more comfortable and safe for workers.
\end{abstract}

Key-words: Comfort. Insalubrity. Heat. Brick factory. 


\section{INTRODUÇÃO}

Segmento responsável pela produção de peças cerâmicas e porcelanas (blocos e telhas), as olarias constituem fornecedoras essenciais para a execução de obras no ramo da Construção Civil. Seu processo produtivo consiste na moldagem e queima da matériaprima, visando obter um material que atenda aos requisitos previstos na norma ABNT NBR 15.270:2005 no que diz respeito a características físicas, mecânicas, geométricas, entre outras.

Para o processo de queima necessário à execução do referido procedimento, as empresas do setor utilizam fornos que emitem altas quantidades de calor, responsáveis pela queima que provoca as reações necessárias à aquisição de resistência mecânica, durabilidade, entre outras características. A temperatura, neste caso, influencia diretamente na qualidade do produto final e faz-se, portanto, essencial ao processo produtivo.

Tendo em vista a necessidade de segurança e conforto durante a execução das atividades dos funcionários, a intenção deste estudo é promover melhorias no local de análise, buscando evitar a ocorrência de acidentes, bem como de consequências futuras para a saúde dos trabalhadores. Visa, portanto, a elaboração de sugestões e correções dos aspectos insalubres observados, que são os causadores destas consequências.

Para que se pudesse sugerir mudanças na rotina e no ambiente de trabalho, foi necessário realizar uma análise crítica da situação da empresa, verificar se os dados coletados condiziam com as especificações e limites estabelecidos pela norma e, portanto, se proporcionavam bem-estar aos colaboradores. Para este fim, foi preciso avaliar os fatores de risco e de insalubridade presentes no cotidiano das atividades. Riscos estes aos quais os funcionários são continuamente submetidos. E não somente como caso excepcional do seguinte estudo, a exposição ao calor em olarias também foi citada por Diniz (2012) e Medeiros (2012).

Mediante a necessidade de controle dos fatores de risco existentes, a Norma Regulamentadora $\mathrm{n}^{\circ} 15$ - NR 15 (BRASIL, 2007) estabelece limites de tolerância e condições a serem considerados de acordo com a insalubridade presente no ambiente de trabalho e a agressividade da atividade executada. A comparação dos valores dispostos em norma com os dados obtidos a partir da pesquisa de campo fornece um panorama da situação da empresa, e o diagnóstico, pode gerar sugestões de alterações na rotina dos funcionários, objetivando a melhoria do ambiente de trabalho.

Desta forma este artigo teve como objetivo analisar os níveis de calor e conforto dentro de uma olaria no sul do Brasil, a fim de comparar os valores e parâmetros encontrados com as normas vigentes e sugerir melhorias.

\section{FUNDAMENTAÇÃO TEÓRICA}

\subsection{Ergonomia}

A Norma Regulamentadora NR-17 do Ministério do Trabalho e Emprego, que versa sobre ergonomia, estabelece parâmetros para a adaptação das condições de trabalhos às características psicofisiológicas dos trabalhadores, visando o máximo conforto, segurança e desempenho eficiente. Incluem-se nessa norma aspectos relacionados ao levantamento, transporte e descarga de materiais, ao mobiliário, aos equipamentos e às condições ambientais do posto de trabalho e até mesmo a própria organização do trabalho. No que diz respeito a condições ambientais de trabalho tem-se (BRASIL, 2014a): 
17.5.2. Nos locais de trabalho onde são executadas atividades que exijam solicitação intelectual e atenção constantes, tais como: salas de controle, laboratórios, escritórios, salas de desenvolvimento ou análise de projetos, dentre outros, são recomendadas as seguintes condições de conforto: a) níveis de ruído de acordo com o estabelecido na NBR 10152, norma brasileira registrada no INMETRO; b) índice de temperatura efetiva entre $20^{\circ} \mathrm{C}$ (vinte) e $23^{\circ} \mathrm{C}$ (vinte e três graus centígrados); c) velocidade do ar não superior a $0,75 \mathrm{~m} / \mathrm{s}$; d) umidade relativa do ar não inferior a 40 (quarenta) por cento.

No que diz respeito ao levantamento, transporte e descarga individual de materiais o que é bastante encontrado dentro de uma olaria, a NR-17, comenta que sempre que possível isso deve ser feito por meios mecânicos e não pelo trabalhador, a fim de se evitar problemas à saúde do mesmo (BRASIL, 2014a).

\subsection{Calor}

Segundo Saliba (2008), o calor é um agente físico e seus limites de tolerância podem ser encontrados na NR-15 em seu anexo 3. Este anexo possui as equações de "Índice de Bulbo Úmido - Termômetro de Globo" - (IBUTG) tanto para ambientes internos como externos, com ou sem carga solar. As medições devem ser realizadas com termômetro de bulbo úmido natural, termômetro de globo e termômetro de mercúrio comum. $\mathrm{O}$ local de medição deve ser onde permanece o trabalhador, à altura da região do corpo mais atingida. Com o IBTUG calculado devem-se consultar os quadros presentes em anexo para a definição dos períodos de trabalho e de descanso. Conforme será apresentado e explicado adiante.

A utilização da NR 15 para obter parâmetros de limites de insalubridade deve ser feita primeiro calculando-se o IBUTG para ambientes internos ou externos sem carga solar (BRASIL, 2014b):

$$
\mathrm{IBUTG}=0,7 \mathrm{TBN}+0,3 \mathrm{TG}
$$

onde, IBUTG = índice de bulbo úmido termômetro de globo em ${ }^{\circ} \mathrm{C}$;

$\mathrm{TBN}=$ temperatura de bulbo úmido em ${ }^{\circ} \mathrm{C}$;

TG = temperatura de globo em ${ }^{\circ} \mathrm{C}$.

Posteriormente calculando-se o IBUTG para ambientes externos com carga solar (BRASIL, 2014b):

$$
\mathrm{IBUTG}=0,7 \mathrm{TBN}+0,1 \mathrm{TBS}+0,2 \mathrm{TG}
$$

onde, $\mathrm{TBS}=$ temperatura de bulbo seco em ${ }^{\circ} \mathrm{C}$.

Tem-se no Quadro 1 os valores de IBUTG que determinam quanto tempo deverá ser dispensado ao trabalho e ao descanso em cada situação. 


\section{Quadro 1 - Atividades e operações insalubres}

\begin{tabular}{|c|c|c|c|}
\hline $\begin{array}{c}\text { Regime de Trabalho } \\
\text { intermitente por hora com } \\
\text { descanso no próprio local }\end{array}$ & $\begin{array}{c}\text { Atividade Leve } \\
\left({ }^{\circ} \mathrm{C}\right)\end{array}$ & $\begin{array}{c}\text { Atividade } \\
\text { Moderada }\left({ }^{\circ} \mathrm{C}\right)\end{array}$ & Atividade Pesada $\left({ }^{\circ} \mathrm{C}\right)$ \\
\hline Trabalho contínuo & Até 30,0 & Até 26,7 & Até 25,0 \\
\hline $\begin{array}{l}45 \text { minutos de trabalho } \\
15 \text { minutos de descanso }\end{array}$ & Entre 30,1 à 30,6 & Entre 26,8 à 28,0 & Entre 25,1 à 25,9 \\
\hline $\begin{array}{l}30 \text { minutos de trabalho } \\
30 \text { minutos de descanso }\end{array}$ & Entre 30,7 à 31,4 & Entre 28,1 à 29,4 & Entre 26,0 à 27,9 \\
\hline $\begin{array}{l}15 \text { minutos de trabalho } \\
45 \text { minutos de descanso }\end{array}$ & Entre 31,5 à 32,2 & Entre 29,5 à 31,1 & Entre 28,0 à 30,0 \\
\hline $\begin{array}{l}\text { Não é permitido o trabalho, } \\
\text { sem a adoção de medidas } \\
\text { adequadas de controle. }\end{array}$ & Acima de 32,2 & Acima de 31,1 & Acima de 30,0 \\
\hline
\end{tabular}

Fonte: BRASIL (2014b)

Segundo Dul e Weerdmeester (1995), em trabalhos mais pesados - a pessoa sente-se melhor em temperaturas mais frias e ocorre o contrário nos trabalhos mais leves.

\section{METODOLOGIA}

Esta pesquisa caracterizou-se como um estudo de caso com levantamentos qualitativos e quantitativos. A primeira etapa da pesquisa foi composta da coleta de informações no ambiente de estudo. Fez-se um levantamento dos dados necessários ao estudo, e estabeleceu-se um plano para a obtenção deste. Definiu-se nesta etapa os locais de medição do calor e observou-se a rotina e as condições de trabalho.

No levantamento de informações necessárias constavam detalhes sobre o lugar (ambientes, equipamentos, postos de trabalho). Além disso, buscou-se compreender as atividades executadas, bem como a rotina e horário de trabalho. Por fim, para a análise de destaque no presente estudo, seria preciso verificar as condições as quais os envolvidos estariam submetidos durante a execução do serviço, condições estas relacionadas ao conforto ambiental, bem como ergonomia e segurança no trabalho. Os aspectos observados envolveram, portanto, questões de salubridade, com foco na exposição ao calor gerado pelos fornos.

Durante o processo os trabalhadores realizavam o transporte de material, processo este que incluía o abastecimento e retirada de blocos cerâmicos nos fornos. Os tijolos, após serem moldados na máquina extrusora, eram carregados manualmente até pallets que, por sua vez, eram movidos por meio de uma empilhadeira aos fornos. Depois eram levados à estufa para aquecimento gradual durante 12 horas. Após esta etapa sofriam um processo de queima sob temperaturas que podiam chegar a $1000^{\circ} \mathrm{C}$ durante 36 horas.

A respeito das condições no transporte de material, verificou-se como era realizado o carregamento dos blocos, bem como quantas vezes era necessário realizar este transporte em um determinado período.

A parte seguinte da pesquisa consistiu em uma verificação dos locais de trabalho. Para tanto, questionou-se a respeito das funções de cada ambiente e seus respectivos equipamentos e a partir do que foi observado desenhou-se um croqui (Figura 1) listando 
os principais aspectos dos lugares e suas funções. A disposição do espaço em estudo possibilitou uma compreensão mais precisa dos aspectos analisados na pesquisa.

Figura 1 - Disposição do local de trabalho

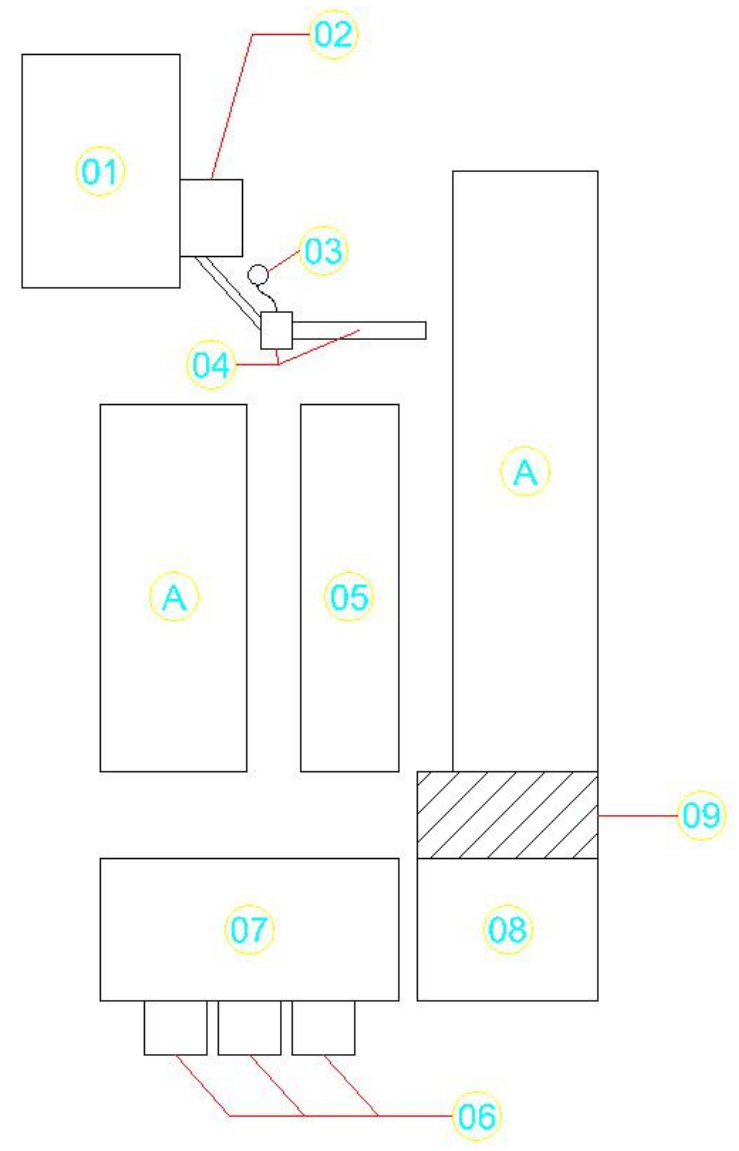

01 - Área de entrada de material;

02 - Misturador;

$\mathbf{0 3}$ - Painel de controle;

04 - Extrusora;

05 - Estufa;

06 - Queimadores;

07 - Forno;

08 - Pilha de carregamento;

09 - Posição do caminhão;

A - Depósito do material finalizado.

Fonte: Matos (2014)

Após a verificação dos aspectos qualitativos da pesquisa (estudo da rotina e atividades de colaboradores, hora de trabalho e condições ergonômicas, bem como grau de agressividade de cada função), partiu-se para a obtenção de dados quantitativos relacionados ao conforto térmico no ambiente, o que possibilitaria por fim $o$ desenvolvimento do projeto.

O equipamento utilizado para as medições foi um Medidor de Stress Térmico, modelo TGD-400, da Instrutherm, com resolução de $0,1^{\circ} \mathrm{C}$ e precisão de $\pm 0,5^{\circ} \mathrm{C}$ (Figura 2). $\mathrm{O}$ equipamento forneceu as temperaturas de bulbo seco, bulbo úmido e de globo, dados com os quais se pode obter o índice IBUTG, parâmetro de comparação com os valores dispostos na NR-15, que estabelece entre outras coisas os limites de tolerância para a exposição a temperaturas extremas no ambiente de trabalho. 
Fonte: Os autores (2014)

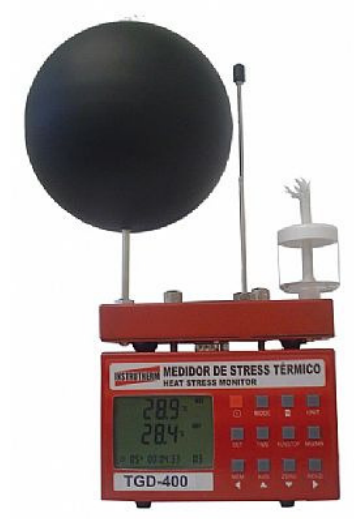

As temperaturas foram obtidas nos postos de trabalho onde os trabalhadores ficavam durante sua jornada de trabalho. Após um período de observação verificou-se que os locais com maior emissão de calor onde haviam pessoas trabalhando eram a entrada do forno, onde acontecia a colocação e retirada dos blocos do processo de queima, e ao lado da pilha de blocos. As medições nestes locais foram feitas durante 1 hora, conforme as normas regulamentadoras, e com o equipamento sobre um tripé, ajustandose sempre a altura do mesmo para que este ficasse na altura da região do corpo mais atingida pelo calor.

Ressalta-se que o termômetro foi colocado nos pontos escolhidos, nos lugares onde estavam localizadas as pessoas durante a execução das tarefas. Deste modo os resultados são tão condizentes com a situação real quanto possível. Os resultados obtidos foram comparados com os limites de tolerâncias para calor expressos na NR-15.

\section{RESULTADOS E DISCUSSÕES}

Questões ergonômicas do processo produtivo, bem como suas etapas de execução, foram fatores importantes a serem analisados para poder estabelecer juntamente com a medição do IBUTG o nível de conforto ambiental existente no local de estudo e, com isso, sugerir possíveis alterações técnicas no contexto atual da olaria.

\subsection{Tempo de parada para descanso dos funcionários}

A jornada de trabalho dos funcionários da empresa analisada consiste em turnos que se iniciam às 7 horas da manhã e vão ininterruptamente até às 9 horas, possuindo então 20 minutos para o café que é oferecido no local. Em seguida retoma-se o processo até às 11 horas e 30 minutos, parando o processo novamente para o almoço de duração de uma hora. $\mathrm{O}$ turno da tarde se inicia às 12 horas e 30 minutos e segue sem pausas até às 15 horas que é quando há a parada para o lanche. Finalizando o processo, tem-se a retomada às 15 horas e 20 minutos que se segue até o final do expediente que se dá às 17 horas e 30 minutos. O número de horas totais trabalhadas por dia é de 8 horas e 50 minutos, já o número de horas descansadas durante o turno de trabalho é de 1 hora e 40 minutos.

Apesar de se haver 3 paradas no turno de trabalho, respeitando o tempo estipulado por lei para o descanso dos operários, nota-se que há um expediente maior do que 8 horas diárias sem o pagamento de adicionais como hora extra. Também não se vê locais adequados para esse descanso, pois a olaria não disponibiliza ambientes de estar. Tais 
fatores conjugados com o alto nível térmico emanado pelos fornos propiciam baixo rendimento de produção, bem como exaustão excessiva.

\subsection{Quantidade de blocos carregados por funcionário}

Os tijolos são transportados em quatro processos distintos de sua produção: o primeiro processo é quando se retira os tijolos da esteira e se leva aos pallets após o material passar pela máquina extrusora; o segundo processo é quando os tijolos são transportados para a sua queima no forno, o terceiro processo é quando os tijolos saem do forno em direção à estufa para serem resfriados e o último transporte se dá quando se carrega os tijolos resfriados às carrocerias dos caminhões de entrega do material. Os funcionários participam manualmente apenas no primeiro e último processo, sendo nos demais processos utilizadas empilhadeiras para o transporte dos pallets carregados e um suporte com trilhos para a entrada dos tijolos ao forno. Observou-se que no primeiro processo de retirada dos tijolos da esteira, cada funcionário retirava dois tijolos por vez e os colocava no pallet, havendo em média um total de 32 movimentos repetitivos para se carregar completamente um pallet. Já no último processo também manual, cada funcionário carregava no caminhão uma quantidade de 4 tijolos de 6 furos em cada mão, de modo a agilizar o tempo despendido no processo de transporte.

O carregamento simultâneo de vários tijolos, além de aumentar o peso que o trabalhador tem de aguentar, pode causar danos em longo prazo na coluna dos operários. Além disso, a forma como os dedos sustentam esses tijolos, forma de pinça ao se inserir os dedos das mãos nos furos dos tijolos, pode causar lesões por esforço repetitivo ou distensões. O excesso de peso de carregamentos contínuos suportados pelos trabalhadores em um ambiente excessivamente quente, como no caso da olaria em questão, propicia a percepção de um conforto ambiental insalubre e inadequado para a eficiência produtiva do processo e para a manutenção da qualidade de vida dos funcionários.

\subsection{Tempo de carregamento dos blocos}

Os tijolos carregados pela empilhadeira por meio de pallets ao forno levam em média 3 horas, pois o processo consiste primeiramente em carregar todos os pallets com capacidade máxima para depois levá-los um a um de forma mecânica até o forno. Já o processo de carregamento manual das caçambas dos caminhões dura em média 30 minutos, pois é realizado com 4 a 5 funcionários por vez trabalhando em processo rápido e ininterrupto nesse tempo.

O tempo de 30 minutos de movimento repetitivo ininterrupto no qual os funcionários da olaria são submetidos ao carregar o caminhão é diretamente relacionado com o esforço de carga que os mesmos despendem no processo, a postura corporal adotada e o conforto térmico ambiental no qual são expostos durante a atividade. Como analisado in loco, nota-se que todos os aspectos que envolvem a atividade são normativamente incorretos.

\subsection{Postura corporal de carregamento adotada e carga}

No primeiro processo manual de transporte dos tijolos na esteira para os pallets, observou-se que a postura corporal adotada pelos funcionários era inicialmente de pé com o dorso inclinado e torcido, pois os pallets se concentravam imediatamente atrás da esteira rolante, já à medida que se carregava a parte inferior do pallet, a postura corporal passava a ser em pé com o dorso reto e torcido. Vale ressaltar aqui que com essas posturas os operários carregavam 2 tijolos de 6 furos por vez, o que equivale a um total 
de $3,6 \mathrm{~kg}$. No último processo que também se caracteriza como sendo manual, observou-se que a postura adotada pelos trabalhadores ao se carregar as caçambas dos caminhões de entrega eram de pernas retas e dorso inclinado ou de pernas retas, dorso inclinado e torcido. Vale ressaltar também que com essas posturas os operários carregavam em média 4 tijolos de 6 furos em cada mão, o que equivale em um total de $7,2 \mathrm{~kg}$ por membro superior. Em ambos os processos tem-se movimentos corporais caracterizados como sendo repetitivos com carregamento de peso.

Conforme NR- 17 que versa sobre o levantamento, transporte e descarga de material $10 \%$ do peso corporal carregado já é causador de problemas de coluna, como o caso do carregamento observado pelos funcionários da olaria. A norma também estabelece que a postura adequada para o carregamento de material deve ser mantendo a coluna como suporte e não a curvando e nem promovendo movimentos de torção como foi observado na atitude dos funcionários. As posturas inadequadas dos funcionários conjuntamente com o excesso de peso nesse processo são fatores que agravam a percepção de espaço insalubre e maximizam a sensação do nível de calor no qual os mesmos são diariamente submetidos.

\subsection{Idade média dos trabalhadores e tempo de permanência}

Mediante entrevista com o dono da olaria, soube-se que a empresa consta com um total de 10 funcionários homens, estando todos com idades entre 18 e 27 anos. O tempo de permanência na empresa não ultrapassa 5 anos, exceto com os dois rapazes que são filhos do dono da olaria que trabalham lá desde os 14 anos de idade.

Como o trabalho executado é basicamente de esforço físico, os funcionários contratados acabam sendo jovens e homens por aguentarem uma maior carga em relação ao seu peso corporal. O tempo de permanência dos mesmos na empresa é relativamente curto, representando uma alta rotatividade no quadro de funcionários devido a alguns fatores como: baixa remuneração, longa distância de trajeto para o trabalho, condições psicossociais desfavoráveis e absenteísmos em decorrência da monotonia no processo produtivo e da exposição contínua aos altos níveis de calor.

\subsection{Percepção do ambiente fabril}

Nota-se que o uso de luvas térmicas se encontrava de acordo com o disposto na norma, porém ainda era necessário o uso de proteção auricular aos funcionários que são expostos constantemente aos ruídos próximos à máquina extrusora, à estufa e ao forno (87,4 dB(A) medido com decibelímetro ao lado do forno). Além disso, nota-se um ambiente fabril relativamente precário, onde a iluminação é somente natural devido às circunstâncias de produção serem apenas durante o dia, dificultando a visibilidade da atividade no inverno, período em que escurece mais cedo. Quanto à ventilação se percebe o uso de ventilação natural no ambiente de trabalho e somente artificial na estufa onde se tem o resfriamento das peças, porém devido à presença constante de fuligem saída do forno diretamente para o ambiente, deveria haver um sistema de filtro desse resíduo para que não haja prejuízos respiratórios em longo prazo aos trabalhadores.

\subsection{Resultados da avaliação do calor}

Mediante visita técnica realizada em 07/02/2014 na Olaria Cachimba, pode-se coletar os seguintes dados (Quadro 2) referentes à temperatura ambiente de exposição na qual os operários do barracão são diariamente expostos. Nota-se que como o ambiente possuía a 
influência de radiação solar, utilizou-se para o cálculo do IBUTG a equação que contempla a temperatura de bulbo úmido, bulbo seco e globo.

\section{Quadro 2 - Dados obtidos in loco por meio do IBUTG}

\begin{tabular}{|c|c|c|c|}
\hline Local & $\begin{array}{c}\text { Temperatura de bulbo } \\
\text { seco, }{ }^{\circ} \mathbf{C}\end{array}$ & $\begin{array}{c}\text { Temperatura de bulbo } \\
\text { úmido, }{ }^{\circ} \mathbf{C}\end{array}$ & $\begin{array}{c}\text { Temperatura de } \\
\text { globo, }{ }^{\circ} \mathbf{C}\end{array}$ \\
\hline Ao lado do forno & $32,3^{\circ} \mathrm{C}$ & $23,2^{\circ} \mathrm{C}$ & $34,8^{\circ} \mathrm{C}$ \\
\hline $\begin{array}{c}\text { Ao lado da pilha } \\
\text { de tijolos }\end{array}$ & $44,0^{\circ} \mathrm{C}$ & $26,2^{\circ} \mathrm{C}$ & $42,9^{\circ} \mathrm{C}$ \\
\hline
\end{tabular}

Fonte: Os autores (2014)

O trabalho realizado tanto próximo ao forno, quanto ao lado da pilha de tijolos é considerado pesado, pois os carregamentos manuais por funcionário duram em média 30 minutos de trabalho intermitente com aproximadamente $14,4 \mathrm{~kg}$ de carga sendo constantemente erguida e depositada na carroceria do caminhão de entrega. Os valores de IBUTG obtidos foram de aproximadamente $26^{\circ} \mathrm{C}$ (ao lado do forno) e $31^{\circ} \mathrm{C}$ (ao lado da pilha de tijolos), estando ambos acima dos limites de tolerância estabelecidos pela NR-15 para trabalhos contínuos sem pausas. Nota-se que a temperatura externa obtida foi de $22^{\circ} \mathrm{C}$ o que equivale a $4^{\circ} \mathrm{C}$ a menos em relação à temperatura observada ao lado do forno e $9^{\circ} \mathrm{C}$ a menos em relação à temperatura ao lado da pilha de tijolos.

Nota-se que pelos valores encontrados na situação ao lado do forno, o trabalhador deveria ter como rotina trabalhar 30 minutos e descansar 30 minutos a cada hora trabalhada. Já na condição "ao lado da pilha de tijolos", o trabalho segundo a NR-15 não seria permitido, por ser muito desgastante, ou seja, insalubre. Recomenda-se neste caso, primeiramente um rearranjo do layout do ambiente de modo a permitir uma maior ventilação natural, amenizando os efeitos maléficos do alto índice de calor interno. Em segundo caso, podem-se implantar nos pontos analisados barreiras radiantes perimetrais de material isolante térmico.

\section{CONCLUSÕES}

Primeiramente pode-se concluir que o trabalho executado dentro da olaria nos postos de trabalho em que se mediu o calor (IBUTG), é insalubre nas condições em que hoje é executado, perante a NR-15 do Ministério do Trabalho e Emprego, sendo termicamente desconfortável para o trabalhador, visto os elevados índices de temperaturas detectados.

Observou-se ainda diversos aspectos transgredidos quanto à questão de conforto ambiental dentro desta olaria. Portanto, devem-se aplicar mudanças organizacionais na empresa tais como: filtros de fuligem adequados ao forno utilizado, palestras explicativas referentes às posturas corretas para a atividade executada, análise da direção dos ventos para reposicionar os postos de trabalho favorecendo a ventilação, distanciar o posicionamento do carregamento de tijolos do forno e da estufa para amenizar o calor submetido pelos trabalhadores, distribuir proteção auricular aos funcionários que operam nas máquinas e próximo a elas, criar ambientes de estar para o descanso nas pausas da execução, distribuir os 50 minutos excedentes de trabalho em pausas no carregamento dos tijolos para diminuir o esforço físico dos trabalhadores, utilizar uma camada mais espessa de material refratário para amenizar o calor emanado ao ambiente e melhorar a vedação das aberturas do forno. 


\section{REFERÊNCIAS}

BRASIL. Ministério do Trabalho e Emprego. NR 15 - Atividades e operações insalubres. Manual de Legislação Atlas. São Paulo: Blucher, 74a. edição, 2014a.

BRASIL. Ministério do Trabalho e Emprego. NR 17 - Ergonomia. Manual de Legislação Atlas. São Paulo: Blucher, 74a. edição, 2014b.

DINIZ, Rodrigo Barbosa. Análise documental sobre a insalubridade em olarias de Corumbá: um estudo dos processos do TRT $-\mathbf{2 4}^{\mathrm{a}}$ região - 1968. Rev. Hist. UEG - Goiânia, v.1, n.1, p.213-221, jan./jun. 2012.

DUL, Jan.; WEERDMEESTER, Bernard. Ergonomia prática. São Paulo: E. Blücher, 1995.

IIDA, ITIRO. Ergonomia - Projeto e produção. $2^{\text {a }}$ edição revisada e ampliada, São Paulo, Editora Edgard Blücher, 2005.

MEDEIROS, Leydja Dayane Dantaset et al. Estudo ergonômico numa indústria de cerâmica vermelha no estado do Rio Grande do Norte. VII SEPRONE "A Engenharia de Produção frente ao novo contexto de desenvolvimento sustentável do Nordeste: coadjuvante ou protagonista?", Mossoró-RN, 2012.

SALIBA, T. M. Curso Básico de segurança e higiene ocupacional. São Paulo: LTR, 2008.

SANTOS, NÉRI; FIALHO, FRANCISCO. Manual de Análise Ergonômica do Trabalho. Curitiba: Gênesis, $2^{a}$ ed., 1997,316p.

SCHMIDT, Frank W.; HENDERSON, Robert E; WOLGEMUTH, Carl H. Introdução às ciências térmicas: termodinâmica, mecânica dos fluidos e transferência de calor. São Paulo: Blucher, 1996. 